\title{
Práxis Do Ensino Na Educação Básica Diante De Adolescentes Usuários De Drogas
}

\author{
Practices OfTeaching In Basic Education \\ Before Adolescents Drug Users
}

\author{
Rafael Pasche da Silveira' $\bullet$ Janice Sarubbi de Moraes $^{2}$ \\ Marlene Gomes Terra ${ }^{3}$ Valquiria Toledo Souto ${ }^{4}$ \\ Adão Ademir da Silva ${ }^{5}$ - Daiana Foggiato De Siqueira ${ }^{6}$
}

\section{RESUMO}

Objetivo: Compreender a práxis de educadores que vivenciam o processo de ensino-aprendizagem diante de adolescentes usuários de drogas. Método: Pesquisa qualitativa realizada educadores de uma Escola de Ensino Fundamental de um município do estado do Rio Grande do Sul, Brasil. Os dados foram coletados de abril a junho de 2014, por meio de rodas de conversas, inspiradas no círculo de cultura de Paulo Freire, e analisados simultaneamente, mediante análise temática. Resultados: Emergiram duas categorias: Uso de drogas e suas consequências na realidade de educadores e educandos; e, Práxis dos educadores diante de adolescentes usuários de drogas. Conclusão: No cotidiano de ensino, o educador reconhece-se como um sujeito vulnerável e em sofrimento, necessitando de apoio e valorização. Isto porque o ambiente escolar está envolto por mudanças no tipo e padrão de uso de drogas pelos adolescentes, o que foi relacionado ao desinteresse para aprender e aumento da violência.

Descritores: Adolescente; Transtornos relacionados ao uso de substâncias; Ensino; Docentes; Enfermagem.

\begin{abstract}
Objective:To understand the praxis of educators who experience the teaching-learning process in front of adolescent drug users. Method: Qualitative research carried out by educators of a Elementary School of a municipality in the state of Rio Grande do Sul, Brazil. The data were collected from April to June 2014, by means of conversation wheels, inspired by Paulo Freire's culture circle, and analyzed simultaneously, through thematic analysis. Results: Two categories emerged: Drug use and its consequences in the reality of educators and learners; and, Praxis of educators before teenage drug users. Conclusion: In everyday teaching, the educator recognizes himself as a vulnerable and suffering subject, needing support and appreciation. This is because the school environment is surrounded by changes in the type and pattern of drug use by adolescents, which was related to the lack of interest in learning and the increase in violence.
\end{abstract}

Keywords: Adolescent; Substance-related disorders; Teaching; Teachers; Nursing. 


\section{INTRODUÇÃO}

A escola desempenha um papel fundamental na formação das pessoas, que vai além da função de instrução, ou seja, contribui, também, com a construção das relações sociais. Uma das fases da vida que compreende o período escolar é a adolescência. $O$ Estatuto da Criança e Adolescente (ECA) estabelece que esse período situa-se entre 12 e 18 anos incompletos. É uma fase no processo de desenvolvimento que ocasiona novas descobertas, conflitos, experiências de crises e rupturas que trazem à tona a vulnerabilidade e fragilidade dos educandos no estabelecimento de vínculos e relações sociais. Os educadores percebem que um fenômeno que está cada vez mais presente na sociedade e vem refletindo em dificuldades à sua práxis no ambiente escolar é o envolvimento de adolescentes com o uso de drogas ${ }^{(1-2)}$.

O contexto das drogas engloba mais que o fato do consumo da substâncias em si, pois está atrelado a alta prevalência de violência sofrida ou praticada entre os adolescentes no ambiente $^{(3)}$. No Brasil, algumas pesquisas foram realizadas em busca de evidenciar o panorama do consumo de substâncias entre os adolescentes em idade escolar. A Pesquisa Nacional de Saúde do Escolar, de uma amostra com estudantes do $9^{\circ}$ ano do Ensino Fundamental, revelou que $66,6 \%$ dos escolares pesquisados já haviam experimentado bebida alcoólica, sendo que as Regiões Sul $(76,9 \%)$ e a Centro-Oeste $(69,8 \%)$ apresentaram os maiores índices ${ }^{(4)}$. Já os dados do último levantamento sobre o consumo de drogas psicoativas entre estudantes do Ensino Fundamental e Médio das escolas públicas e privadas brasileiras apontaram que $25,5 \%$ dos adolescentes relataram já ter usado alguma droga ilícita na vida, $10,6 \%$ no último ano e $5,5 \%$ no mês anterior à entrevista. Em relação ao álcool, $60,5 \%$ relataram uso na vida, $42,4 \%$ relataram uso no último ano, e $21,1 \%$ relataram uso no mês anterior à entrevista ${ }^{(5)}$

Estudos nacionais e internacionais têm apontado a correlação entre uso de drogas e problemas escolares, como faltas, repetências, evasão escolar, dificuldade de aprendizagem e pouco comprometimento com as atividades escolares ${ }^{(6-7)}$. Além disso, a escola acaba convivendo com outros problemas sociais que se aproximam desse contexto, como gravidez na adolescência, desemprego, fome, violência doméstica, dentre outros que colaboram para a existência e expressão de um ambiente que retrata essa vulnerabilidade social( ${ }^{(8)}$.

O meio escolar gera processos educativos para além da produção de informação e conhecimento, colaborando com o desenvolvimento de cidadania e de transformação social. Espaço que permite aos educadores despertar para a importância do desenvolvimento de ações educativas e preventivas no contexto das drogas. No entanto, os mesmos, por vezes, encontram desafios na abordagem dessa temática em seu contexto laboral. Cita-se às representações sociais que associam drogas e violência; as questões pessoais como à falta de conhecimentos específicos e de metodologias para abordagem, e; a falta de apoio institucional frente ao investimento pela gestão em ações voltadas à formação profissional(9-10). Todas essas questões dimensionam o desafio posto aos educadores em sua práxis diante de adolescentes em situação de envolvimento com o contexto das drogas.

Para o presente estudo compreendeu-se como fundamental possibilitar aos educadores, que vivenciam um cotidiano condicionado a essas situações que envolvem o contexto de abuso de drogas, um espaço de fala e reflexão sobre sua própria prática. Assim, elencou-se a questão norteadora: como os educadores da educação básica descrevem a sua práxis diante de adolescentes usuários de drogas? Para tanto, definiu-se como objetivo compreender a práxis de educadores da educação básica que vivenciam o processo de ensinoaprendizagem para adolescentes usuários de drogas.

\section{MÉTODO}

Trata-se de um estudo qualitativo, com inspiração na abordagem problematizadora do referencial teórico de Paulo Freire. Os dados foram coletados entre abril e junho de 2014, por meio da realização de quatro rodas de conversas com educadores de uma Escola Estadual de Ensino Fundamental de um município do estado do Rio Grande do Sul, Brasil. A referida escola faz parte do programa Escola Aberta: Educação, Cultura, Esporte e Trabalho para a Juventude, do Ministério da Educação, e desenvolve suas atividades pautada na lógica de inclusão social, acolhendo educandos em condição de vulnerabilidade social, defasagem escolar, moradores de rua, entre outros problemas sociais.

Os critérios de inclusão pré-estabelecidos para seleção dos educadores participantes foram: homens ou mulheres que lecionassem na referida escola, nas turmas da $I^{a}$ à $8^{a}$ serie e Educação de Jovens e Adultos (EJA) que atendessem adolescentes com idades entre 12 e 18 anos. Todos os educadores da escola foram convidados. Dos 16 educadores que preenchiam os critérios, cinco demonstraram interesse em participar.

As informações emergidas durante as rodas de conversas foram gravadas com auxílio de um gravador digital e transcritas manualmente na íntegra, com autorização prévia dos participantes mediante assinatura do Termo de Consentimento Livre e Esclarecido (TCLE).

As rodas de conversas ocorreram nas segundas-feiras ao final das reuniões de equipe, em uma sala reservada da escola com duração média de uma hora. Foram orientadas pelas seguintes questões: "Vocês esperavam trabalhar em um ambiente escolar onde o contexto da drogas fosse tão presente? Como foi o primeiro contato?"

Conforme surgiam os depoimentos, eram problematizados os questionamentos e os próximos encontros iniciavam com uma síntese acerca das reflexões anteriores. Os educadores novamente falavam sobre o cotidiano de ensino da escola, sua práxis e, naturalmente, descreviam suas avaliações e sentimentos em relação aos momentos vividos na escola. As rodas de conversas permitiram que os participantes refletissem sobre as situações limite vivenciadas e pudessem desvelar novas propostas de ação sobre a questão das drogas.

O processo de análise das informações ocorreu simultaneamente com a coleta de dados, fundamentado na proposta operativa de análise temática, que compreende três etapas: pré-análise; exploração do material; tratamento e interpretação dos dados ${ }^{(1)}$. Na pré-análise ocorreu a leitura inicial, e consequentes releituras de todo o material proveniente das transcrições das rodas de conversa, bem como das anotações em diário de campo. Nesta etapa, fezse necessário retomar os objetivos iniciais da pesquisa para encontrar nos depoimentos as ideias que convergiam.

Durante a etapa de exploração do material realizou-se a codificação dos dados brutos, sendo atribuídos temas a cada trecho de depoimentos que remetessem a um núcleo de compreensão mais específico. Para auxiliar nesta etapa 
de análise, os dados foram distribuídos em um quadro sinóptico, contendo o trecho do depoimento e o tema a que o depoimento remetia (que poderia ser uma palavra-chave ou frase). Ainda, como forma de organização, utilizou-se a técnica de identificação cromática dos temas convergentes, que ao final desta etapa, classificaram-se em duas categorias. $\bigcirc$ tratamento e interpretação dos dados tem como embasamento o referencial teórico do educador Paulo Freire, bem como a revisão de literatura sobre os temas emergidos.

Quanto aos aspectos éticos, os educadores participantes assinaram e receberam o Termo de Consentimento Livre e Esclarecido (TCLE) que lhes afirmaram o respeito aos princípios da Resolução $N^{\circ} 466 / 12$. Para preservar a privacidade e anonimato dos educadores envolvidos, no texto foram identificados pela letra 'E' que é a letra inicial da palavra educador, seguida de um número arábico (EI, E2, E3...). A pesquisa foi aprovada pelo Comitê de Ética em Pesquisa com Seres Humanos da Universidade Federal de Santa Maria em 04/04/20 I4, sob o protocolo CAAE N²8 I 0 I I |4.5.0000.534.

\section{RESULTADOS}

Os educadores participantes do estudo contemplaram quatro mulheres e um homem que possuíam idades entre $45 \mathrm{e}$ 57 anos, com tempo de serviço na escola entre dois a 18 anos. Além disto, dos cinco participantes, quatro referiram possuir vínculo como educador em outra instituição.

As duas categorias que emergiram da análise dos dados foram: Uso de drogas e suas consequências na realidade de educadores e educandos; Práxis dos educadores diante de adolescentes usuários de drogas.

\section{Uso de drogas e suas consequências na realidade de educadores e educandos}

A realidade vivenciada pelos educadores desta escola relaciona-se com as consequências do uso de drogas pelos adolescentes que se expressa no ambiente de trabalho e nas relações educando-educador. Com o passar dos anos, essa escola passou por mudanças para ser incluída como integrante do projeto Escola Aberta, vindo a acolher encaminhamentos de adolescentes em defasagem de idade/série e situação de vulnerabilidade. Para esses educadores, esse cenário alterou a realidade de trabalho na escola, sendo influenciada pela mudança no perfil de uso de drogas dos adolescentes. Para os educadores, um novo panorama configurou-se com a presença do crack, afetando as relações entre educadores e educandos:

"A gente não trabalhava tanto com essas drogas como hoje em dia, era uma situação adversa... E, hoje em dia, essa questão dessa droga [crack], essas coisas mudaram muito nosso trabalho" (EI)

"Quando era outro tipo de droga [cola], eles criavam vínculo com a gente. Hoje não mais! Hoje, eles não se apegam, não criam vínculos. Talvez eles gostem de ti num minuto, mas eles podem sair ali e logo passa" (E3)

Diante do cenário assim percebido, os educadores sentemse vulneráveis às situações de violência e oprimidos em seu ambiente de trabalho.

"Uma vez uma menina pegou uma faca e riscou todo o capô do carro da nossa colega. Aí outro lá jogou uma pedra perto de outra colega" (EI)
"Agora na nossa realidade o menino vem duro de crack. A gente tem que aguentar na sala de aula, não consegue dar aula! [relata uma história de violência fisica sofrida] Eu me senti sozinha, enquanto me insultavam eu estava machucada e quem estava na minha frente estava vendo que eu estava sangrando, eu não vi” (E2)

"Tu não tinhas a violência. Eles não estavam contra a gente, eles estavam com nós, éramos pontos de referência" (E3)

Outra consequência descrita pelos educadores como influenciada pelo contexto de uso de drogas é a alteração na aprendizagem em sala de aula:

"Por exemplo, a tabuada do dois, tu dá hoje, amanhã tu dá exercício, amanhã eles não lembram mais.A memória deles está afetada!"(E3)

"Com relação a drogadição e ao aprendizado, tu não consegue avançar.A dificuldade deles é muito grande!”(E4)

Uso de drogas e suas consequências na realidade de educadores e educandos foram entendidos pelos participantes como situações de vulnerabilidades incluindo as questões de violência e opressão em seu ambiente de trabalho, implicando em alteração na aprendizagem em sala de aula.

\section{Práxis de educadores diante de adolescentes usuários de drogas}

A práxis dos educadores, compreendida como uma sistemática inter-relação entre teoria e prática ${ }^{(12)}$, ao buscar transformar a realidade em que estão inseridos foi identificada pela consciência de seu papel enquanto facilitadores de transformações, também por meio do conhecimento compartilhado com os adolescentes acerca das drogas. Nesse sentido os educadores reconhecem a importância de terem conhecimento sobre as drogas:

"É um conhecimento que a gente tem que passar para eles, para eles terem pelo menos o conhecimento das coisas" (EI)

"Outro dia eles falaram do dedo amarelo, daí eu disse: olha, isso que faz o amarelo é o alcatrão, e onde ele está? Está no piche, que faz o asfalto da rua, ele que faz o amarelado dos dedos"(E2)

Os educadores também sinalizam a necessidade de fugir de métodos tradicionais de ensino, já notoriamente ineficientes:

"A metodologia normal não funciona com eles. Então temos que inovar, achar maneiras que se consiga tocar" (E5)

Ainda, reconhecem que a abordagem da temática das drogas deve ser feita com base na realidade vivenciada pelo adolescente, e se mostram conscientes do significado que a droga adquiriu em suas vidas:

"Eles têm uma vida tão cheia de maleficios, que a droga é a parte boa. É a hora que eles não têm fome... se a droga não fosse boa eles não iriam usar... Essa coisa a gente está consciente" (El)

"Como é que tu vai chegar e dizer que aquilo ali [droga] não é bom? Na ótica dele [adolescente], ele vai dizer que é muito bom, ele gosta, ele sai de si, ele se libera, enfim, na concepção dele é ótimo. Não tem como dizer que é ruim!"'(E5) 
Além de reconhecer o educando em sua realidade, o enfrentamento desse contexto pelos educadores também acontece pelo diálogo aberto, franco, como referem:

"Uma coisa que é legal que a gente faz aqui, é tão natural que a gente não se dá conta: a gente fala da droga com muita tranquilidade... é legal porque a gente consegue ter essa abertura" (EI)

Mesmo com todos os problemas do ambiente de ensino, sentem esperança que todo trabalho realizado na escola não seja em vão:

"E quando a gente encontra os alunos que já passaram por aqui e que estão vencendo, com suas dificuldades, mas estão vencendo, dá uma massageada no ego" (E2)

"Nós temos que ter esperança sim! Mas também só esperança não resolve nada. Tem que ter ação e eu estou otimista com o que estamos fazendo, eu acho que é esse o caminho" (E5)

A práxis de educadores sinaliza a importância de o educador ter conhecimento sobre a temática das drogas e pauta-se na realidade vivenciada pelo adolescente usuário de drogas, desviando-se dos métodos tradicionais de ensino. Ainda, revela que os educadores enfrentam essa situção com diálogo aberto, franco e com esperanças da efetividade das suas atividades.

\section{DISCUSSÃO}

Os resultados da pesquisa demonstram como se incorporam no cenário escolar as representações sociais contemporâneas acerca de usuários de drogas, especialmente de drogas ilícitas, como o crack. $\bigcirc$ uso de crack é um fenômeno complexo que envolve discussões do âmbito da saúde, da educação, da segurança e da assistência social, dentre outras instâncias. De acordo com o II Levantamento Nacional de Àlcool e Drogas, dois milhões de brasileiros já usaram cocaína fumada (crack/ merla/oxi) ao menos uma vez na vida(13). Dentre os diversos grupos e segmentos sociais vistos como vulneráveis ao envolvimento com o crack estão os adolescentes.

Nos últimos anos, o tema tem ganhado destaque na mídia, pela vertente de um discurso moralizante, que descreve os usuários como violentos, amedrontadores e delinquentes, contribuindo na construção de representações sociais sobre a droga e o usuário.Autores apontam que esse tipo de imaginário sobre o crack leva à estigmatização e amplia a marginalização dos usuários, limitando a compreensão do fenômeno ${ }^{(14)}$.

Por diversos momentos na história o medo foi utilizado como um freio para o comportamento das sociedades e dos indivíduos. No cenário da escola, inicialmente, o medo foi usado pelo professor como forma de poder sobre o aluno. Atualmente, vê-se um fenômeno inverso, o educador detentor do poder legitimado socialmente, tem se tornado um amedrontado no seu ambiente de trabalho(15), e os atravessamentos relacionados ao uso de drogas influenciam essa nova relação.

Ao mesmo tempo em que essa situação inibe o potencial de educar por ser um dificultador desse processo, há por vezes a reprodução de um estigma associado ao adolescente usuário de crack. Este frequentemente é visto como um peso pela sociedade, isto por ser considerado o culpado por usar drogas $^{(16)}$. Nesse contexto, percebe-se uma ambivalência no ser oprimido no ambiente escolar: por um lado, um adolescente oprimido pelo seu contexto de vida e condicionantes e, por outro, o educador oprimido por lecionar com uma realidade adversa, muitas vezes, sem o apoio político-governamental necessário.

A consequente fragilidade das relações entre educadores e educandos, evidenciada nos resultados, levanta demandas que transcendem a questão do ensino e aprendizagem. $\bigcirc$ papel da escola se amplia para abarcar o processo de conhecerensinar-aprender, de autoridade, de liberdade, de leitura contextualizada do mundo, de virtudes, de identidade cultural dos educandos e respeito frente às diferenças.

Sem capacitar e promover conhecimentos sobre os temas do cotidiano dos educadores constata-se um educador fragilizado para o enfrentamento das questões referente as drogas. Dentre os desafios para os educadores está a exigência de um conhecimento que nem sempre lhes foi oferecido em sua formação( ${ }^{(17)}$. Assim, corre-se o risco de não assumirem a tarefa deste enfrentamento. Destaca-se, a necessidade de um trabalho intersetorial e a transversalização de temas relacionados à saúde mental na formação dos educadores.

O suporte às escolas diante da complexidade de demandas que surgem no ambiente escolar tem encontrado reforço com a criação do Programa Saúde na Escola (PSE), um investimento governamental promissor que propõe a aproximação entre educação-saúde, a partir da atuação de profissionais de saúde dentro de escolas, desempenhando ações de avaliações clínicas, psicossociais, nutricionais, de saúde bucal, realização de atividades físicas, educação sexual e de promoção de saúde e prevenção ao uso de drogas ${ }^{(18)}$. Entretanto, é necessário que essas iniciativas assumam caráter de um fazer compartilhado, promovendo ações integradas, de múltiplas trocas entre profissionais de saúde-educandos-educadores-famílias.

Quanto às dificuldades de aprendizagem também descritas pelos educadores como consequência do uso de drogas no organismo, sabe-se que estas são influenciadas por fatores individuais, pelo tipo de substância utilizada, o padrão de uso, o ambiente, entre outros. As alterações físicas/psíquicas decorrentes do uso podem ser agudas ou crônicas, e podem estar associadas a quadros de disfunções orgânicas que interferem na capacidade de aprendizado e memorização, como descrito no depoimento dos educadores E3 e E4(19).

Um estudo realizado com estudantes de dois municípios do estado de São Paulo, Brasil, demonstrou existir correlação entre as variáveis uso de substâncias e repetências, falta de concentração, notas baixas, desejo de abandonar a escola, sentir-se entediado no ambiente escolar, não fazer os deveres, faltar/chegar atrasado e prejuízos acadêmicos decorrentes do uso de $\operatorname{drogas}^{(7)}$.

Este contexto evidencia que os obstáculos encontrados também ultrapassam aspectos estruturais, encontrando limites em questões de dificuldades subjetivas de aprendizagem do educando. Enfrentar os desafios da função, estar sempre em crescimento com renovação de ideias frente a um cotidiano de realidades difíceis que enfrentará são atitudes permanentes e necessárias ao educador ${ }^{(20)}$.

Abordagens que tem se mostrado mais efetivas na prevenção do uso de drogas são aquelas em que os adolescentes têm a oportunidade de trabalhar formas de lidar com os desafios do ambiente escolar, como: timidez, conflitos geracionais, 
comunicação, agressividade das pessoas, decisões pessoais e escolares. Esses são fatores emocionais mais comuns na adolescência que podem levá-los a experimentarem drogas, esperando que estas diminuam a tensão que esses desafios trazem $^{(3,19)}$.

meio escolar caracteriza-se por relações de poder e pela troca de ideias, e também pela circulação de diferentes concepções de educação e metodologias de ensino. Acreditase que os princípios educativos que mais corroboram para uma prevenção significativa são aqueles que se aproximam de uma abordagem libertadora de educação. Essa abordagem apresenta uma relação mais horizontal entre quem educa e quem é educado, onde ambos são sujeitos da prática educativa, que se desenvolve em um processo dialógico de construção de saberes, embasada por relações democráticas e construção de uma sociedade mais justa e igualitária(21).

Para além de estratégias que melhoram a relação ensinoaprendizagem dentro da escola, é necessário atuação de todos os envolvidos na comunidade que está condicionando essa situação. Coordenadores, professores, pais, funcionários da escola, os próprios educandos e a comunidade em geral precisam ser instigados a promover espaços de cuidado, de promoção de saúde, de lazer, de parcerias que potencializem mudar essa realidade.

Ressalta-se, ainda, que no processo de ensino-aprendizagem o educador não pode assumir um papel de opressor, nem impor padrões morais, mas sim, instrumentalizar o educando para que esse possa refletir sobre a realidade e tomar suas próprias decisões, de forma mais consciente ${ }^{(19)}$. Além disso, é necessário refletir sobre fatores que podem ser protetores para esses educandos visando à prevenção do uso de drogas, como fortalecimento de laços familiares, inclusão social por meio de acesso a cultura, esporte, lazer, promoção de debates sobre perspectivas do futuro e projetos de vida para esses adolescentes.

O trabalho com um educando em situação de vulnerabilidade necessita estar alicerçado em uma educação problematizadora, dialógica, com caráter reflexivo e crítico para que esse educando possa se tornar um agente modificador da sua história(21). Para que os educadores consigam construir esse diálogo aberto com os adolescentes, bem como instigarlhes o interesse no processo de ensino, é fundamental o estabelecimento de vínculo e de relações de afetividade. $O$ ato de ensinar requer afeto. Quando existem amor e carinho, aprende-se melhor ${ }^{(20)}$.

Entende-se que os educadores dessa escola trabalham com muitas dificuldades e, frente a isso, tentam superar barreiras de uma realidade hostil de forma esperançosa. Ter esperança relaciona-se diretamente com a práxis, pois enquanto necessidade ontológica precisa da prática para tornar-se realidade histórica. Paulo Freire problematiza que não há esperança na pura espera, mas quando o ser humano vive uma relação dialética entre condicionamentos e liberdade, a esperança atua como agente de transformação da realidade ${ }^{(22)}$.

Destaca-se que, mesmo frente ao sofrimento do cotidiano de ensino e as dificuldades encontradas, estes educadores permanecem em constante esforço para que o processo de ensino e aprendizagem seja transformador na realidade dos educandos que lá estudam. Os resultados deste estudo deixam clara a existência de um ambiente desafiador ao ato de ensinar, que não é peculiar somente a esta escola, mas compreendido como um problema que permeia o ensino. Ao mesmo tempo, revela o comprometimento destes trabalhadores em considerar a educação enquanto caminho para a transformação da realidade, não fugindo deste que é um compromisso social.

\section{CONCLUSÃO}

Os resultados desta pesquisa permitiram concluir que 0 ambiente escolar está envolto em novos desafios, diante das consequências que as vulnerabilidades sociais que repercutem no envolvimento com drogas trazem aos educandos. Nessa escola, os educadores acreditam que as mudanças no padrão de uso e na substância utilizada, pelos adolescentes, desencadearam maior violência e desinteresse para aprender.

As alterações comportamentais são vistas como responsáveis pela deterioração do vínculo entre educador e educando. No cotidiano de ensino, o educador reconhece-se como um sujeito vulnerável e em constante sofrimento.

Compreende-se que o enfrentamento dessa nova realidade exige educadores criativos que busquem ir além dos padrões tradicionais de ensino.É preciso traçar estratégias para estimular a autonomia e tomada de decisões mais conscientes, a partir da realidade na qual educandos estão inseridos, considerando o significado que estes atribuem ao uso de drogas.

A pesquisa também contribui para reafirmar a importância do educador em sua função social, e da escola como um lugar de construção de cidadania. O sucesso que estes atores/ espaços terão no desempenho de seu papel depende do alicerce proporcionado, tanto pelas políticas de Estado, que incentivem a valorização do ensino, quanto pelas famílias e sociedade, que são corresponsáveis nesse processo.

Este estudo traz como limitação a não realização de entrevistas individuais e em um único cenário de pesquisa, o que pode ter suprimido alguns achados, mas ilustra satisfatoriamente como alguns educadores descrevem sua práxis diante de adolescentes usuários de drogas. Por esse motivo, sugere-se que outros estudos possam explorar diferentes perspectivas desses atores acerca do seu papel, suas consequências diretas e indiretas de educar em um cenário de desigualdades sociais e uso de drogas, as possibilidades de mudanças na formação e estratégias inovadoras nesse contexto.

\section{REFERÊNCIAS}

1. Malta DC, Oliveira-Campos M, Prado RR, Andrade SSC, Mello FCM, Dias AJR et al. Psychoactive substance use, family context and mental health among Brazilian adolescents, National Adolescent School-based Health Survey (PeNSE 20I2). Rev Bras Epidemiol. [Internet] 2014 [citado 2019 Mar 20]; I7(SI):46-6I. Disponível em: $\quad$ http://www.scielo.br/scielo.php?script=sci_ arttext\&pid=SI 4 I5-90X20 I 4000500046\&lng=pt.

2. Moreira A,Vóvio CL, Micheli D. Prevenção ao consumo abusivo de drogas na escola: desafios e possibilidades para a atuação do educador. Educ. Pesqui., São Paulo [Internet]. 2015 [citado 2019 Mar 20]; 4I(I):II9135. Disponível em: http://www.scielo.br/pdf/ep/ v4In I/I5 I7-9702-ep-4I-I-01 I9.pdf

3. Beserra MA, Carlos DM, Leitão MNC, Ferriani MGC. Prevalence of school violence and use of alcohol and other drugs in adolescents. Rev. Latino-Am. Enfermagem [Internet]. 2019 [citado 2019 jul 03]; 27:e3।I0. Disponível em: http://www.scielo.br/pdf/ rlae/v27/0104-I I69-rlae-27-e3 I I0.pdf

4. Brasil. Ministério da Saúde. Pesquisa Nacional de 
saúde do escolar 2015. Coordenação de População e Indicadores Sociais - Rio de Janeiro: IBGE; 2016. I32 p. Disponível em: https://biblioteca.ibge.gov.br/ visualizacao/livros/liv97870.pdf

5. Carlini ELA, Noto AR, Sanchez ZM, Carlini CMA, Locatelli DP et al.VI Levantamento Nacional sobre o Consumo de Drogas Psicotrópicas entre Estudantes do Ensino Fundamental e Médio das Redes Pública e Privada de Ensino nas 27 Capitais Brasileiras. São Paulo: SENAD; 2010.

6. Latimer W, Zur J. Epidemiologic trends of adolescent use of alcohol, tobacco, and other drugs. Child Adolesc Psychiatr Clin NAm [Internet]. 2010 [citado 2019 Mar 25]. 19(3): 45I-464. Disponível em: http://www.ncbi. nlm.nih.gov/pubmed/206822I4

7. Cardoso LRD, Malbergier A. Problemas escolares e o consumo de álcool e outras drogas entre adolescentes. Psicol Esc Educ [Internet]. 2014 [citado 2019 Mar 20]; I8(I): 27-34. Disponível em: http://www.scielo.br/pdf/ pee/vl8nl/vI8nla03.pdf

8. Abramovay M, Castro, MG. Drogas nas escolas: versão resumida. Brasília: UNESCO, Rede Pitágoras; 2005. I43 p.

9. Moreira A,Vovio CL, Micheli, D. Prevenção ao consumo abusivo de drogas na escola: desafios e possibilidades para a atuação do educador. Educ. Pesqui. [Internet]. 2015 [citado 2019 Out 25]; 4I(I), II9-I35. Disponível em:https://dx.doi.org/I0.I590/SI5I797022015011670

10. Silva PMC, Galon T; Zerbetto SR, Moura AAM,Volpato RJ, Gonçalves, AMS. Percepções, dificuldades e ações de professores frente às drogas na escola. Educ. Pesqui. [Internet]. 2018 [citado 2019 Out 25]; 44(el820I5): I 16. Disponível em: http://www.scielo.br/pdf/ep/ v44/I5I7-9702-ep-44-el820I5.pdf

11. Minayo MCS. O desafio do conhecimento: pesquisa qualitativa em saúde. $14^{\mathrm{a}}$ ed. São Paulo (SP): Hucitec; 2014.

12. Fortuna $\bigvee$. A relação teoria e prática na educação em Freire. Rev. Brasileira de Ensino Superior [Internet]. 2015 [citado 2019 Mar 22]; I(2): 64-72. Disponível em: https://seer.imed.edu.br/index.php/REBES/article/ download// 056/746

13. Instituto Nacional de Ciência e Tecnologia para Políticas Públicas de Álcool e Outras Drogas (INPAD). II Levantamento Nacional de Álcool e Drogas (LENAD) - 20I2. Ronaldo Laranjeira (Org.), São Paulo: INPAD, UNIFESP. 2014
14. Romanini M, Roso A. Midiatização do crack e estigmatização: corpos habitados por histórias e cicatrizes. Interface (Botucatu) [Internet]. 2014 [citado 2019 Marc 22]; I8(49), 363-376. Disponível em: http:// dx.doi.org/I0.I590/I807-57622013.0138

15. I5. BALDINO,Angela. Relação Professor-Aluno: Quem amedronta quem? Rio de Janeiro: UFSJ, 2010.

16. I6. Fonseca FF, Sena RKR, Santos RLA, Dias OV, Costa SM. As vulnerabilidades na infância e adolescência e as políticas públicas brasileiras de intervenção. Rev Paul Pediatr [Internet]. 2013 [citado 2019 Abr 5]; 3 I (2):258-64. Disponível em: http://www.scielo.br/pdf/ $\mathrm{rpp} / \mathrm{v} 3 \mathrm{In} 2 / 19 . \mathrm{pdf}$

17. Cordeiro ILS, Silva DMA, Vecchia MD. A escola diante do aluno que faz uso de álcool e drogas: $O$ que dizem os professores?. Pesquisas e Práticas Psicossociais [Internet]. 2016 [citado 2019 Mar 22]; II(2): 356-368. Disponível em: http://pepsic.bvsalud. org/scielo.php?script=sci_arttext\&pid=SI809$89082016000200007 \& \operatorname{lng}=p t \& t \mid n g=p t$.

18. Gaze VAM, Robaina JVL. O impacto do Programa Saúde na Escola: uso da Escala Likert para avaliar os resultados das ações de saúde pública nos alunos de uma escola pública do bairro de Ceilândia, Distrito Federal, sob o aspecto do uso de substâncias ilegais. Rev Espacios [Internet]. 2017 [citado 2019 Abr 4]; 38(45): I0. Disponível em: http://www.revistaespacios. com/a I7v38n45/a I7v38n45pl0.pdf

19. Brasil. Ministério da Justiça. Efeitos de substâncias psicoativas: módulo 2. In: Duarte PCAV, Formigoni MLOS /Organizadoras. SUPERA: Sistema para detecção do Uso abusivo e dependência de substâncias Psicoativas: Encaminhamento, intervenção breve, Reinserção social e Acompanhamento I I.ed. - Brasília: Secretaria Nacional de Políticas sobre Drogas, 2017. $146 \mathrm{p}$.

20. Freire P. Professora, sim; Tia, não: Cartas a quem ousa ensinar. I ${ }^{\mathrm{a}}$ ed. Rio de Janeiro (RJ): Paz e Terra; 2013.

21. Freire P. Pedagogia do oprimido. $50^{\mathrm{a}}$ ed. Rio de Janeiro (RJ): Paz e Terra; 20I I.

22. Freire P. Pedagogia da esperança: um reencontro com a pedagogia do oprimido. $17^{\mathrm{a}}$ ed. Rio de Janeiro (RJ): Paz e Terra; 20 I I. 